\title{
"Double-tap, 'That Was Really Dope'": A Conversation on Breaking on Instagram with Tsiambwom Akuchu and Alexandra Harlig
}

Tsiambwom Akuchu, Independent Artist, Atlanta, GA

Alexandra Harlig, University of Maryland

Conversation held 15 April 2021, via Zoom

Keywords: Bboying, Social Media, Hip-Hop community, pandemic-era screendance

Alexandra Harlig: I follow you on Instagram and I wanted to talk about how you've been thinking about your practice and how filming is part of that. Could you tell me a little bit about what you were doing before Covid in terms of posting online or engaging with other dancers through video?

Tsiambwom Akuchu: Covid's definitely been the speeding up of what's already been happening, and it's also been an expansion of who's been in the digital dance space, especially for Hip-Hop dancers. Prior to Covid, I actually wasn't particularly engaged on Instagram. I had just started really engaging digitally and posting videos and engaging with the community at large that way. I'd been really focused in school until then. I had just gotten out of the grad program and I finally had all this time. I was like, "Well, I should engage with the platform that I've been on for a while now." The Hip-Hop world has really shifted into the digital space very quickly, hard and fast, so it's been a really neat way to connect with other dancers, which I was kind of doing before as well. Once you tag something, everybody can see it, and then it puts you in communication with everybody else who's dancing.

Alexandra: Whether you want to or not.

Tsiambwom: Yeah, this is true, but it's also really cool because there are a lot of barriers that are taken down; you can get somebody pretty big who comments on your work. As a result of me posting more and engaging more online, some OG heads in the b-boy world have been, not reaching out, but they've been commenting and being like, "Hey, I see your stuff," and I'm like, "Oh, cool, yeah, thanks." So, it's been really cool to have that connection. But, prior, I had been working more in live work in physical space. My work itself is a little different because I blend mediums so much that it doesn't quite live in any one space whether I'm engaging with b-boys at a cypher' or modern dancers in a studio. 
Alexandra: So, when we were allowed, were you sessioning ${ }^{2}$ with people live?

Tsiambwom: Definitely. It's sort of dictated by where I am geographically because my MFA was in Montana; a lot of work I've done has been in predominantly white spaces, so it's been hard to find a community of Hip-Hop dancers. We started to build a small but decent Hip-Hop community in Missoula, Montana. We didn't necessarily have resources, so a lot of cyphering and events would happen in parties and whatnot; we engaged with it more socially than we did as practice or battling or training.

Alexandra: So, in lieu of that social session experience, when you're filming your daily practice, are you thinking of it as a social thing, a way that you're putting something out there so people can engage with it? Is it a documentary thing so you can see, "What am I doing? What do I need to work on?" Is it kind of a performance? Is it all of the above?

Tsiambwom: I would say all of the above, depending on head space and what you're going to be doing in the practice session. There was actually a really interesting discussion that I got into on Instagram with B-Boy Wicket, he's been in the community for 30+ years at this point. He posted this question about recording dance practices and if that's a viable practice, if it's necessary, "What do you guys think about it?" So, there was a discussion with b-boys, some of them were against it because you take yourself out of the space when you're supposed to be engaging with other people, and you usually are practicing with a crew, and so they can be your immediate feedback. I responded that, "Well, it really depends because you can find yourself in a place where you have no access and no resources like l've been, and you don't know how to engage with people." And so, having the ability to record what you're doing is helpful, one, for critical feedback, at least for yourself so you can look at it. But secondly, it helps you plug into everybody else. If you post on social media, then there's this expanded cypher that happens where it's like, suddenly, anybody can, if they want to, engage with it like you're walking down the street and you see a bunch of b-boys practicing. They can be like, "Oh, hey, check that out. I see what you're doing." Or, they can just keep going on and scroll past you. So, it redefines how we're engaging socially. But, you can post it as a performative clip. You pick a song that you want to do, then you create a piece of work to it. That starts to fall more in the world of screendance and whatnot. Or, you can just put it out there for your own.

What I started doing at the beginning of the pandemic was just keeping a personal diary, almost a daily log. The \#365Challenge is one of the reasons I started engaging more as well because I was trying to find a way to keep myself more accountable now that I was outside of school. I was constantly in another state within the next three months. I was like, "How do I keep myself accountable for the work I'm doing?" I turned to digital platforms because having to post each day was a drive, I guess, a thing that pushed me to do it. But, it also meant that I had to figure out how to generate my own work, how to find a way to practice or train or at least engage with my movement practice in some form in order to post it on there. 
Alexandra: You had started that before the pandemic, right? Which is really interesting because then you had something to continue as opposed to having to invent something.

Tsiambwom: Yeah, and having the structure of a daily dance post was helpful. You can obviously gear it towards what you want to focus on, so mine was just sort of a broad, "I want to post a dance video a day." If you keep it as a training log, you can say, "Here's my head spin progression. Here's my windmill progression." And you see a lot of that too on Instagram. I scroll through and I follow a lot of b-boys and they'll be like, "This is where I am with my air flares today. This is where I am with my windmills, my head spins, my power combos." Same deal, you get to engage with them and be like, double-tap, "That was really dope," or, "Hey, I've gotten tips from other b-boys who are like, 'You've got to straighten out that leg if you really want to whip around for that windmill.' I see where you're balancing on your head spin. Try reorienting your hands. Try arching your back for your balance," so that happens as well. You can get this communal feedback on how you're doing.

Alexandra: An important part of sessioning is that everybody has their own style, but also, they're in different places with their skills. And so, in the best case, when people are generous and you've really got a communal feeling, people will share and are open to feedback. Hearing you talk about the progression of power moves, ${ }^{3}$ l just remember being in a session and somebody would finally get something. You'd look over and this feeling of jubilation...

Tsiambwom: Everybody gets hype.

Alexandra: Not just the person who did it, but everybody!

Tsiambwom: Oh, yeah. I recently captured one of those moments in my Instagram post because I've been training a transition, a pop move transition, and I finally clicked. I was sessioning with my crew, but we were doing an Instagram Live just for fun. We were having a session and doing some training and I finally got the movement in the middle of it. We all just erupt because I did it and I know I did it. But then, across the room, they're like, "Whoa!" You see my friend hopping across the video like, "That was so cool!" So, one person's success isn't just theirs. It's everybody's.

Alexandra: Obviously, it's not possible to have the exact same experience, but do you feel like that kind of being attuned to people and pumping people up is also happening in the online space?

Tsiambwom: Yes. Obviously, the immediate feedback isn't there, so the level of excitement tapers off. But, you'll get people that comment. That's the hype. That's the pumping up of the moment. Also, it's really interesting because you can go back and relive that moment over and over-l'll go back to a dancer's post and I'll just keep watching it because I'm like, "Wow, that was so cool." It's a little limiting because 
sometimes it doesn't feel like you've captured the moment correctly by just posting . There's some interesting emoji combinations as people try to describe the way they're feeling and hype up the person; you might get the wind emoji with fire $b$, or on power moves, you get the tornado emoji $\$$. It's hard to convey an adequate amount of wonder or excitement or fantasticalness? You get that space star shooting one 1 sometimes like, "That was out of this world. That was crazy."

Alexandra: When you're together the reaction is usually so embodied, with the hand props, or you're sitting down but you jump up, and there's a lot of vocalization. That has to be flattened in a way because of the platform.

Tsiambwom: Absolutely. Initially, I had an apprehension about digital platforms particularly because the community aspect of Hip-Hop, the way you engage with people, gets lost a little bit. There's something to be said about the sharing of the space, being next to each other one-on-one. It's almost in a ritualistic sense. There's this meditative sense that you all are plugged into, that you can't get when it's all electronic.

Alexandra: Have there been attempts to do Zooms, like synchronous sessions?

Tsiambwom: It's hard to do a cypher, but they've been playing around with battle formats. Especially at the beginning of the pandemic they started doing Instagram Live battles where it's, "I dance. You dance. I dance. You dance," like in a battle. But, just through the medium, there's going to be degradation of the quality of video and you can't quite see what that one dancer did, or, if the internet cuts out then you're just dancing in a void or you're not watching anything. If one person's playing the music from their end, there's a delay on the other end, and then you suddenly lose an element of the dance that's required to judge it, which is musicality. So, there's been a couple of experiments, but they died out pretty quickly because of the hurdles.

Alexandra: And in battles there are so many nuances to the response system, so if you're missing part of what your opponent is doing, then that's a lot harder to key into. Maybe that's also one of the things you're practicing when you're sessioning, is being attuned to what other people are doing.

Tsiambwom: Yeah, you pick up on how to react and how to engage by being in the space with other people. Online, everybody's sort of doing their own thing. Not that you're not observing from your own unique perspective, but there isn't an implicit understanding of the rules of how you're sharing in it.

Alexandra: Whereas, in person, you think the etiquette is more understood?

Tsiambwom: Yeah, cypher, jam, battle etiquette, all that isn't fully articulated. It tends to still live in the world of oral history, and it differs regionally. So it's hard to just pin down specifically how you're supposed to be in a cypher. It's something you learn by being in one. 
Alexandra: Having to articulate rules for a new context could be hard if the previous rules are not explicitly articulated. On the point of trying-to-get-the-cypher-feel, is that how you found DanceFight? ${ }^{4}$

Tsiambwom: Honestly, I don't know how I got half the apps on my phone. I think it probably was an Instagram ad that redirected me towards it. It's pretty difficult to structure battles on a digital platform, and so I was wondering what their approach was going to be. I was really interested that it took the sort of TikTok format. I was trying to engage with it because part of me was like, "This could actually be a really, really great tool, especially pandemic-wise to try and recreate the idea of a battle or a cypher in a way that connects more people."

Alexandra: And what did you think of it?

Tsiambwom: There are ups and downs. Actually, the people who were developing it reached out to me, and they wanted some thoughts on it; they were really focused on dancers engaging with each other. I conferred with my dance crew and as a spokesman, I sent over our collective thoughts on it. We were thinking about all the things that make a cypher a cypher, what it is we do when we're battling each other and what's going on there, and then thinking of how to translate that into an app, which is really difficult. I haven't fully fleshed out my thoughts on DanceFight yet, but I sort of have an eye on it-it's pretty new and I'm sure they're going to learn and grow over time. They've been steadily developing a base of users from what I've seen. One thing that I found in the beginning was that there wasn't necessarily a distinction between when it was community dancing versus people battling or engaging with more of a battle mindset.

Alexandra: Because anyone can engage with any video. Is that right?

Tsiambwom: Yeah, anyone can engage with any video at any given time, and so you can have people just enjoying the music put up against somebody who's going really hard to the music. What I do like is the voting system: you swipe on the one you prefer. As a form of engagement, it brings the audience into it like you would in a cypher. I may not be able to be like, "Whoa, you did something really cool," but I can swipe, which I thought was really great execution. But that's one thing that I think will need to really get fleshed out on the app because the thing with TikTok and DanceFight now, the dancing that happens on there isn't necessarily technical dancing. It's more community dancing, the way I see it anyways. Everybody's like, "You should go on TikTok." I'm on it, but there's a difference in the way l engage with dance and the way the majority at large engages with dance. Some of the most famous dancers who have been in the community forever have the smallest following on TikTok.

Alexandra: It's not a freestyle-based ecosystem. 
Tsiambwom: Not at all. There isn't necessarily room for improvisation. And there's no whole body, right? Where do you pinpoint technique to anything if you can't really see the full body in action?

Alexandra: Thinking about your posts where you're trying out windmills-it literally wouldn't fit. The camera would have to be so far away.

Tsiambwom: I feel like, to create a TikTok video, you've got to be right there. The aesthetic of it, but also the experience of it is this up-close in-your-face kind of thing, and there's an aesthetic distance that exists when you're improvising or freestyling or engaging with dance that's necessary to really enjoy it because you got to see the whole body at work, see what's happening.

Alexandra: I think you mentioned on Instagram that you've had some problems getting into a flow when you're aware of the camera.

Tsiambwom: Yeah, I've been interrogating that lately because it's something I hear reflected with a lot of other dancers: "the camera turns on and everything I know goes out the window." I'm so confused about the phenomenon because, when I'm in a cypher with my crew or at a jam, it's a lot of eyes on you, but you're able to engage your brain fully in the way you want to in the dance form. But then, with the camera, you can't tell if anything you're doing is good or not. Usually, when you know someone's watching, you can expect a reaction. But, with the camera, you know something is watching, but it's not watching to engage.

Alexandra: It doesn't know anything about how to be in a breaking space; it's like having a situationally illiterate person-a new person, to say it neutrally-come into a space and just stand there.

Tsiambwom: Yeah, and just stare really hard.

Alexandra: Don't say anything. Don't make any noise.

Tsiambwom: There's probably a lot more to it psychologically, especially because there's, I guess, a conflict that exists between doing something communal-based, but as a solo practice sort of because it's just you and the camera.

Alexandra: Do you similarly feel like you're in a different head space just by virtue of being alone even if you don't have the camera on?

Tsiambwom: Yeah, for similar reasons. The camera is probably the most difficult part, but what l've been focusing on over the past year is learning how to just work by myself when I don't have anybody that could respond to me. There's a creative energy that doesn't exist when you're by yourself that makes it harder to plug into the dance, and I've actually come to enjoy the challenge of it because it's really forced my brain to be like, "So, what am I doing?" It's suddenly like, "What is dance and what is it to you and 
what does it mean to just be a body moving?" If there is nobody to engage with it, are you really still dancing or are you just flailing on the floor trying to figure something out? Yeah, I guess that's the really scary thing about it, is the existential place it puts you in.

Alexandra: Alternatively though, is there any freedom to it? If you aren't going to post something or if you're not recording it, can you care less about messing up or pausing?

Tsiambwom: Yeah, it took me a second to learn, leaning into failing and being more comfortable with that because you tend to be your own worst critic and don't have somebody to balance that, that'll pile up on you. Just creating work with a camera is really helpful because then you can fail more. But, if there's a failure, you can really develop something interesting.

Alexandra: So, are you typically filming a whole hour or something, and then you choose what to post from that?

Tsiambwom: Sometimes I'm like, "I want to see that move again," and I'll do short recordings of a specific move set. But for the most part, in my training sessions, I like to warm up with a freestyle for 10-15 minutes and just let the camera go. And then, later on, I'll be like "Ah, I like this section. I'll post this section." If I look through it and I don't like anything, I don't have to post every day, is where I've landed with that; I want to post something that's an interesting concept that I was playing with. I'll keep sections I want to look at again whether to see my technique, or if I'm trying to create something that's specifically to be experienced through a phone screen.

Alexandra: A general critique about social media broadly, but especially Instagram because of its visual-centric culture, is that people post the best of everything. Do you find in your own posting an impulse towards putting your best foot forward, and do you see that in other people, or are people posting falling out of a head spin or whatever?

Tsiambwom: I think in general because a lot of people are going to watch it, you want to post something that is the best representation of who you are. Prior to the pandemic, that's what I would do. But, at least in my personal practice, over the course of the pandemic, I've been learning to post as a work-in-progress rather than a finished product. There is a section of the community that engage in that way, they'll say, "Check it out. I've been working on something. I'm failing, but I feel good about the work I'm doing," and leaning into failing as a natural process of learning.

Alexandra: When people were getting together in person, they were able to fail semipublicly in a session and get feedback there, and then this more finished product thing was happening online. But now, there isn't that other outlet.

Tsiambwom: I think there's a bigger fear in posting work that has flaws in it, partially because it's everybody, not just your specific community that gets to engage with it. 
Alexandra: Do you think that you're going to keep up these practices as you are able to be more co-present with people?

Tsiambwom: Yes, at this point, I've integrated it into my personal routine, as a dancer, and part of it is curating my online presence. I hadn't thought about it too much before, it'll be harder to switch out, than to just keep going with using it as an accountability tool. Social media for me has become a log of my personal journey, but also a way of seeing my work develop. It's become a super useful tool.

\section{Biographies}

Tsiambwom " $\mathrm{T}$ " Akuchu is a hip-hop/theatre artist and activist based in Atlanta, Ga whose work has been presented on stages like the Kennedy Center and Joe's Pub at The Public. His work spans various forms of theater and dance, from Commedia to Hip Hop. As a hip-hop artist, he choreographs and creates work for the concert stage that utilizes hip-hop and black vernacular dance blended with classical, modern, and post-modern dance that creates deeply personal work rooted in his culture as a Cameroonian native and his experiences in the United States. He is currently investigating solo practice as a hip-hop dancer. See more of his movement practice on Instagram @tsebwom and @somaticbboy.

Website: www.akuchu.com

Alexandra Harlig is an Assistant Clinical Professor at University of Maryland in the University Honors 'Virtually Human' thematic cluster. She holds a PhD in Dance Studies from The Ohio State University. Her research focuses on popular dance forms in media: the political and economic analysis of their production, circulation, and reception, the movement cultures captured, and the platforms utilized. She sessioned with the Cornell University breaking crew Absolute Zero while an undergraduate student. Find her on the internet @ReadyMadeAl

Email: aharlig@gmail.com

Website: https://alexandraharlig.com/ 
Notes

${ }^{1}$ Cyphers are informal, unjudged competitions that anyone present can join into. They may happen at a party, on the street, or on the side at an organized breaking event.

${ }^{2}$ Sessioning, or going to (a) session, is the usual pedagogical model for breaking, as well as House and many other Hip-Hop and Funk styles; it involves people sharing a space and music, mostly working on their own to master movement vocabulary or work on putting moves together, but with feedback and encouragement from the other dancers.

${ }^{3}$ Power Moves are those more acrobatic moves that display strength and flexibility, including a range of flips and spins.

${ }^{4}$ DanceFight is an app which debuted in 2020, that allows dancers to go up against each other with posts to the same music. Other users determine who won the matchup by voting. 